\title{
Thymoquinone, the Nigella sativa Bioactive Compound, Prevents Circulatory Oxidative Stress Caused by 1,2-Dimethylhydrazine in Erythrocyte during Colon Postinitiation Carcinogenesis
}

\author{
Hanene Jrah Harzallah, ${ }^{1}$ Rahma Grayaa, ${ }^{1}$ Wafa Kharoubi, ${ }^{2}$ Aya Maaloul, ${ }^{1}$ \\ Mohamed Hammami, ${ }^{2}$ and Touhami Mahjoub ${ }^{1}$ \\ ${ }^{1}$ Research Unit of Cancer Biology and Genetics, Hematologic, and Autoimmune Diseases, Faculty of Pharmacy of Monastir, \\ University of Monastir, 5000 Monastir, Tunisia \\ ${ }^{2}$ Research Unit of Human Nutrition \& Metabolic Disorder, USCR Mass Spectrometry, Faculty of Medicine of Monastir, \\ University of Monastir, 5000 Monastir, Tunisia
}

Correspondence should be addressed to Hanene Jrah Harzallah, jrahhanene@yahoo.fr

Received 1 December 2011; Revised 7 January 2012; Accepted 30 January 2012

Academic Editor: Ersin Fadillioglu

Copyright (C) 2012 Hanene Jrah Harzallah et al. This is an open access article distributed under the Creative Commons Attribution License, which permits unrestricted use, distribution, and reproduction in any medium, provided the original work is properly cited.

We have performed this study to investigate the modulatory effect of thymoquinone (TQ), the Nigella sativa active compound, on erythrocyte lipid peroxidation and antioxidant status during 1,2-dimethylhydrazine- (DMH-) induced colon carcinogenesis after initiation in male Wistar rats. Rats exposed to DMH showed an increase of malondialdehyde and conjugated diene levels, and an augmentation of enzyme activities like catalase, glutathione peroxidase, and superoxide dismutase activities was also noted. The TQ pretreatment restored the parameters cited above to near-normal values. However, the posttreatment shows an activity similar as that presented by DMH. Therefore, our investigation revealed that TQ was a useful compound preventing DMH-induced erythrocyte damages.

\section{Introduction}

Antioxidants such as glutathione, $\alpha$-tocopherol, ascorbic acid, superoxide dismutase, catalase, and peroxidase are formed within cells to prevent the harmful effects of reactive oxygen species (ROS), such as superoxide anion radical $\left(\mathrm{O}_{2}{ }^{-\bullet}\right)$ hydroxyl radical $(\bullet \mathrm{OH})$, and peroxyl radical (ROO•), which are continually generated in vivo both by aerobic metabolism and exogenous sources such as UV radiation, environmental pollution, and diet [1]. Oxidative stress produced by free radicals has been associated with the development of several diseases such as cardiovascular, cancer, and neurodegenerative diseases [2]. Colorectal cancer is among the leading causes of cancer-related death and one of the most commonly diagnosed cancers in western developed countries [3]. 1,2-Dimethylhydrazine (DMH), a potent colon carcinogen, undergoes oxidative metabolism resulting in the production of electrophilic diazonium ion, which is known to elicit oxidative stress in the RBCs [4]. In recent years, much effort has been dedicated to a search for natural or pharmacological preventive agents, which would block or attenuate colorectal cancer process [5]. Epidemiological and experimental studies demonstrate the importance of compounds derived from plants in reducing the risk of colon cancer [6] and inhibit the development and the multiplicity of tumors in experimental animals [7]. Nigella sativa $L$. is an annual herbaceous plant belonging to the Ranunculaceae family, commonly used traditionally in Middle Eastern folk medicine as a natural remedy for various diseases for over 2000 years [8]. Thymoquinone (TQ) was the abundant Nigella sativa essential oil compound and known to be the active principle responsible for many of the seed's antioxidant and anti-inflammatory effects [3]. TQ has been revealed to have promising antitumor effects. It inhibited the incidence of fibrosarcoma tumors in mice induced with 20methylcholanthrene as well as forestomach tumors induced 
with benzo(a)pyrene [9, 10]. The study of Badary [11] has demonstrated that TQ attenuates ifosfamide-induced Fanconi syndrome in rats, enhances its antitumor activity in mices and increase, the antitumor effects of ifosfamide. Furthermore, TQ was shown to reduce cisplatin-induced nephrotoxicity without disturbing its antitumor activity [12]. Blood is the principal tissue in human body wherever abnormal modification in its parameters indicates the toxic effects of drug chemicals leading to diseases. In fact, changes in RBCs have been detected in a number of human pathologic conditions or after exposure to xenobiotics displaying oxidative stress. Erythrocytes are permanently in contact with potentially damaging levels of oxygen, but their metabolic activity is capable of reversing this injury under normal conditions, which are equipped by many defense systems representing their antioxidant capacity [13]. This protective system includes superoxide dismutase (SOD), catalase (CAT), reduced glutathione, glutathione peroxidase (GPx), glutathione-S-transferase, and glutathione reductase (GR) [14]. Oxidation of erythrocytes includes membrane injury, methemoglobin formation, osmotic fragility, and the destruction of the cell [15]. Further, oxidative stress in red blood cells is an indicator of overall oxidative stress besides RBC-related disorders. Thus, the present study investigates the potential protective and curative effect of TQ in erythrocyte oxidative damage in postinitiation $\mathrm{DMH}$ colon cancer in rats. So our funding assesses (1) the hematological parameters count, (2) the levels of MDA, in terms of thiobarbituric acid reactive substances (TBARS), (3) the conjugated diene level, and (4) the activities of antioxidant enzymes in the RBCs.

\section{Material and Methods}

2.1. Animal Experimental Design. Adult male Wistar rats were bred in the animal care facility at the Faculty of Pharmacy of Monastir (Tunisia). Rats were housed under optimum conditions of temperature set at $22 \pm 2^{\circ} \mathrm{C}$ and light set at 12 hrs light-dark cycle. Rats were kept in plastic cages covered with sawdust and had unrestricted access to a commercial rat diet $(24 \%$ protein, $4.5 \%$ fat, and $4 \%$ fiber) and water. All animal studies were conducted using a protocol approved by the Institutional Animal Care and Use Committee of the Faculty of Pharmacy of Monastir. The toxicity of TQ in rats was determined prior to the $\mathrm{DMH}$ animal experiment.

2.2. DMH Rat Experiment. One week after acclimatization, the rats were randomly divided into 5 groups of five animals each. Animals were treated once per week either with saline, $\mathrm{TQ}, \mathrm{DMH}$, pretreatment (TQ + DMH) (10 weeks), or posttreatment DMH (10 weeks) + TQ (10 weeks); DMH $(20 \mathrm{mg} / \mathrm{kg} \mathrm{bw})$ was dissolved in isotonic saline and was injected subcutaneously (s.c.) once per week on the dorsal back. TQ ( $5 \mathrm{mg} / \mathrm{kg}$ bw, ) was injected (i.p.) once per week. At the end of experimental period, the animals of different groups were sacrificed by cervical decapitation to avoid stress.
2.3. Blood Samples Preparation. Blood samples were collected into EDTA tubes. Some were immediately used for the quantification of hematological parameters. Others were centrifuged at $2200 \times \mathrm{g}$ for $15 \mathrm{~min}$. Plasma samples were then removed and the sediments containing erythrocytes were suspended in phosphate buffer saline solution $(0.9 \%$ $\mathrm{NaCl}$ in $0.01 \mathrm{M}$ phosphate buffer, $\mathrm{pH}$ 7.4) and centrifuged as reported by Sinha et al. [16]. This process was repeated twice. After removing cells' debris by centrifugation at $3000 \times \mathrm{g}$ for $15 \mathrm{~min}$, the hemolysate were obtained and stored at $-80^{\circ} \mathrm{C}$ until biochemical analysis.

2.3.1. Hematological Study. Red blood cell counts (RBC), white blood cells count (WBC), hemoglobin concentration $(\mathrm{Hb})$, hematocrit $(\mathrm{Ht})$, mean corpuscular volume $(\mathrm{MCV})$, mean corpuscular hemoglobin $(\mathrm{MCH})$, and mean corpuscular hemoglobin concentrations (MCHC) were quantified in an automatic hematological assay analyzer (Beckman Coulter, USA).

\subsection{Biochemical Assays}

2.4.1. Protein Quantification. Protein content in the erythrocytes was determined using Protein-BioRad assay [17] and bovine serum albumin as a standard.

2.4.2. Erythrocyte Lipid Peroxidation. Lipid peroxidation was determined indirectly by measuring the production of MDA in the erythrocytes extract following the method of Yagi, [18]. Briefly, $200 \mu \mathrm{L}$ of hemolysates were mixed with $150 \mu \mathrm{L}$ of TBS (Tris $50 \mathrm{mM}$ and $\mathrm{NaCl} 150 \mathrm{mM}, \mathrm{pH} \mathrm{7.4)}$ ) and $250 \mu \mathrm{L}$ TCA-BHT (20\% TCA and BHT 1\%). The mixture was vigorously vortexed and centrifuged at $1500 \mathrm{~g}$ for $10 \mathrm{~min}$. $400 \mu \mathrm{L}$ of the supernatant were added with $\mathrm{HCl} 0.6 \mathrm{~N}$ and $320 \mu \mathrm{L}$ Tris-TBA (Tris $26 \mathrm{mM}$ and TBA $120 \mathrm{mM}$ ), the content was mixed and incubated $10 \mathrm{~min}$ at $80^{\circ} \mathrm{C}$. The absorbance was measured at $535 \mathrm{~nm}$. The optic density corresponding to the complex formed with the TBA-MDA is proportional to the concentration of MDA and to the lipid peroxide. The concentration of $\mu \mathrm{mol}$ of MDA/mg of proteins is calculated from the absorbance at $535 \mathrm{~nm}$ using the molar extinction coefficient of MDA $1.56 \times 10^{5} \mathrm{M}^{-1} \mathrm{~cm}^{-1}$. Another indicator of the lipid peroxidation is the conjugated diene (CD) which is measured as described by Esterbauer et al. [19]. The results were expressed as $\mu \mathrm{mol}$ hydroperoxides/mg protein.

\subsubsection{Determination of Antioxidant Enzyme Activities}

(1) Catalase Activity. Catalase activity was measured in the hemolysate at $240 \mathrm{~nm}$ and $25^{\circ} \mathrm{C}$ according to [20]. Briefly, $20 \mu \mathrm{L}$ of the hemolysate were added in the quartz cuvette containing $780 \mu \mathrm{L}$ phosphate buffer and $200 \mu \mathrm{L}$ of $\mathrm{H}_{2} \mathrm{O}_{2}$ $0.5 \mathrm{M}$. The activity of catalase was calculated using the molar extinction coefficient $\left(0.04 \mathrm{mM}^{-1} \mathrm{~cm}^{-1}\right)$. CAT activity was calculated in terms of $\mu$ mole $\mathrm{H}_{2} \mathrm{O}_{2}$ consumed/min/mg of protein (Figure 1). 


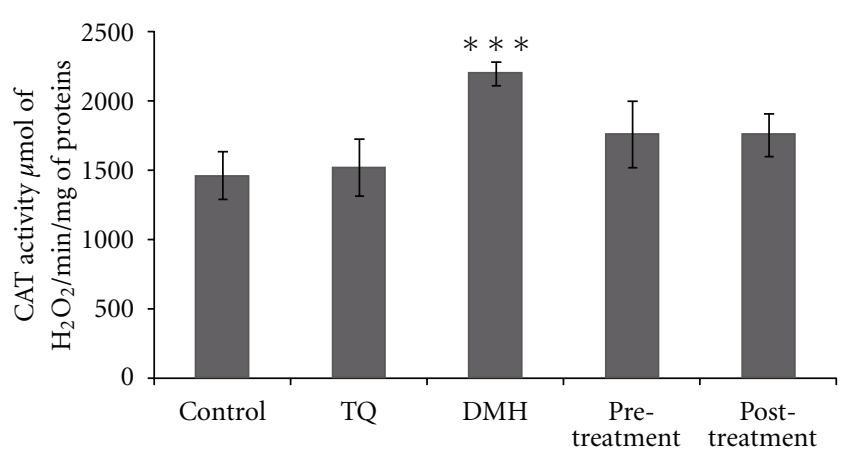

FIGURE 1: Erythrocyte CAT activity in adult rats of controls or treated with $\mathrm{DMH}, \mathrm{TQ}$, and different $(\mathrm{TQ}+\mathrm{DMH})$ treatments. Values are means \pm SE for five rats in each group. $\mathrm{DMH}, \mathrm{TQ}$, and different $(\mathrm{TQ}+\mathrm{DMH})$ groups versus control group: ${ }^{*} P<0.05$; ${ }^{* *} P<0.01 ;{ }^{* * *} P<0.001$, (TQ $+\mathrm{DMH}$ ) groups versus $\mathrm{DMH}$ : ${ }^{+} P<0.05 ;{ }^{++} P<0.01 ;{ }^{++} P<0.001$. U: $\mu$ mol of $\mathrm{H}_{2} \mathrm{O}_{2} / \mathrm{min}$.

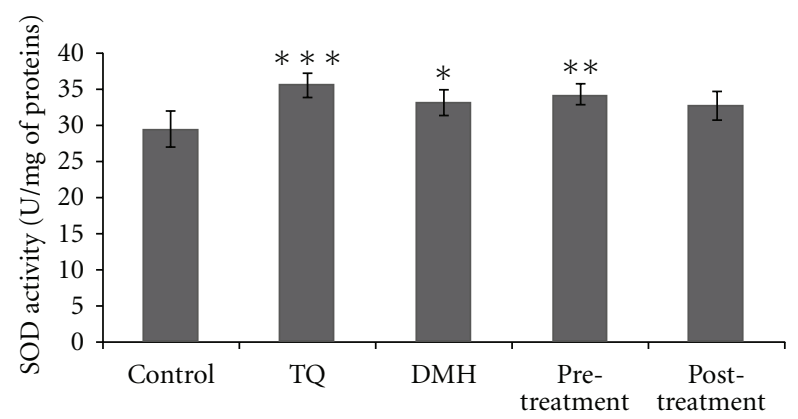

FIgURE 2: Erythrocyte SOD activity in adult rats of controls or treated with $\mathrm{DMH}, \mathrm{TQ}$, and different $(\mathrm{TQ}+\mathrm{DMH})$ treatments. Values are means \pm SE for five rats in each group. DMH, TQ, and different $(\mathrm{TQ}+\mathrm{DMH})$ groups versus control group: ${ }^{*} P<0.05$; ${ }^{* *} P<0.01 ;{ }^{* * *} P<0.001$, (TQ $\left.+\mathrm{DMH}\right)$ groups versus $\mathrm{DMH}$ : ${ }^{+} P<0.05 ;{ }^{++} P<0.01 ;{ }^{+++} P<0.001$. U: Enzyme required for $50 \%$ inhibition of NBT reduction.

(2) Superoxide Dismutase (SOD) Activity. Superoxide dismutase (SOD) activity was estimated according to Beauchamp and Fridovich [21]. The reaction mixture contained $50 \mathrm{mM}$ of hemolysate in potassium phosphate buffer $(\mathrm{PH}$ 7.8), $0.1 \mathrm{mM}$ EDTA, $13 \mathrm{mM}$ L-methionine, $2 \mu \mathrm{M}$ riboflavin, and $75 \mathrm{mM}$ nitro blue tetrazolium (NBT). The developed blue colour in the reaction was measured at $560 \mathrm{~nm}$. Units of SOD activity were expressed as the amount of enzyme required to inhibit the reduction of NBT by $50 \%$, and the activity was expressed as units/mg of protein (Figure 2).

(3) Glutathione Peroxidase (GPx) Activity. Glutathione peroxidase (GPx) activity was measured according to Flohe and Gunzler [22]. The enzyme activity was expressed as nmol of GSH oxidized/min/mg protein (Figure 3).

2.5. Statistical Analysis. The data were analyzed using the Statistical Package for Social Sciences (SPSS) programme, release 17.0 for Windows (SPSS, Chicago, IL, USA). In each assay, the experimental data represent the mean of five

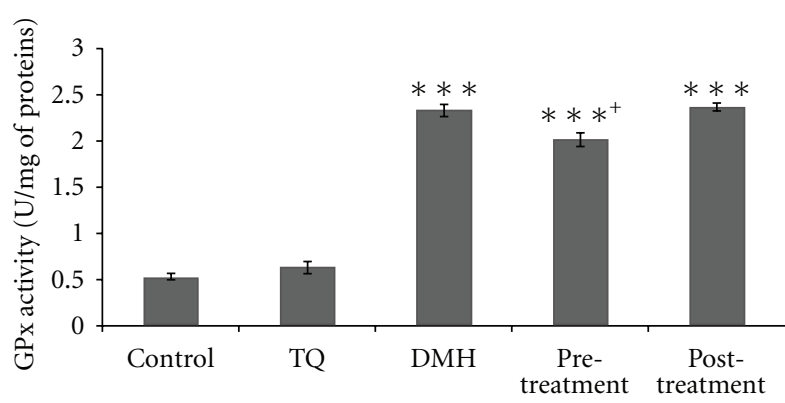

FIGURE 3: Erythrocyte GPX activity in adult rats of controls or treated with $\mathrm{DMH}, \mathrm{TQ}$, and different (TQ + DMH) treatments. Values are means \pm SE for five rats in each group. DMH, TQ, and different $(\mathrm{TQ}+\mathrm{DMH})$ groups versus control group: ${ }^{*} P<$ $0.05 ;{ }^{* *} P<0.01 ;{ }^{* * *} P<0.001$, (TQ $+\mathrm{DMH}$ ) groups versus DMH: ${ }^{+} P<0.05 ;{ }^{++} P<0.01 ;{ }^{++} P<0.001$. U: $\mu \mathrm{mol}$ of GSH oxidized $/ \mathrm{min}$.

independent assays \pm standard deviations. The results were analyzed using Tuckey's test for comparison between the different treatment groups. The statistical significance was set at $P<0.05$.

\section{Results}

3.1. Hematological Parameters. The TQ pretreatment leads to a significant increase in WBC level with $114.57 \%$ and a significant decrease in PLT with $65.89 \%$ compared to control and DMH groups, respectively. The TQ posttreatment causes compared to the control group a significant decrease in RBC number with $23.15 \%$ and a very significant increase in PLT and WBC levels with $394.89 \%$ and $192.3 \%$, respectively (Table 1).

3.2. Lipid Peroxidation in Erythrocytes. All the results from various treatment groups were compared with their normal control. However, results from different (TQ $+\mathrm{DMH})$ groups were also compared with the data of DMH-treated group. During this study, no sign of toxicity was observed under DMH treatment at $20 \mathrm{mg} / \mathrm{kg}$. Rats exhibited normal behavior in comparison to the control group. Our results revealed a significant increase of lipid peroxidation in the erythrocytes of $\mathrm{DMH}$, pretreatment, and posttreatment groups with $35.62 \%, 32.65 \%$, and $53.39 \%$, respectively, compared to control group (Table 2).

3.3. $C D$ in Erythrocyte. Our result shows a significant increase in CD level only in the posttreatment with $40.15 \%$ compared to control. However, the increase was $43.54 \%$ compared to DMH group. The other groups show a nonsignificant difference compared to control or to $\mathrm{DMH}$ group (Table 2).

3.4. Antioxidant Enzyme Activities. All the results from various treatment groups were compared with their normal control. However, results from pretreatment and posttreatment groups were also compared with the data of DMH 
TABLE 1: Hematologic parameters: red blood cell (RBC), hemoglobin (HGB), hematocrit (HCT), mean corpuscular volume (MCV), mean corpuscular hemoglobin concentration (MCHC), mean corpuscular hemoglobin (MCH), platelet (PLT), and white blood cell (WBC) of controls or treated rats with $\mathrm{DMH}, \mathrm{TQ}$, and different $(\mathrm{TQ}+\mathrm{DMH})$ treatments.

\begin{tabular}{lccccc}
\hline & Control & TQ & DMH & Pretreatment & Posttreatment \\
\hline RBC $\left(10^{6} \mathrm{~mm}^{-3}\right)$ & $6.52 \pm 0.46$ & $5.934 \pm 0.94$ & $6.346 \pm 1.1$ & $6.73 \pm 0.39$ & $5.01 \pm 0.78^{*}$ \\
HGB $(\mathrm{g} / \mathrm{dL})$ & $11.48 \pm 0.65$ & $11.18 \pm 1.5$ & $10.74 \pm 1.65$ & $11.66 \pm 0.40$ & $10.88 \pm 1.48$ \\
HCT $(\%)$ & $32.58 \pm 1.63$ & $27.74 \pm 4.36$ & $30.4 \pm 5.62$ & $27.94 \pm 1.38$ & $34.16 \pm 2.86$ \\
MCV $\left(\mu \mathrm{m}^{-3}\right)$ & $47.78 \pm 1.88$ & $47.48 \pm 0.64$ & $47.38 \pm 0.68$ & $47.48 \pm 0.63$ & $52.62 \pm 2.133^{* * *+++}$ \\
MCHC $(\mathrm{g} / \mathrm{dL})$ & $35.40 \pm 0.21$ & $38.1 \pm 1.73$ & $36.4 \pm 0.92$ & $34.48 \pm 1.16$ & $34.08 \pm 1.5$ \\
MCH $(\mathrm{pg})$ & $16.88 \pm 0.60$ & $17.98 \pm 0.88$ & $17.16 \pm 0.36$ & $18.24 \pm 1.36$ & $17.9 \pm 0.78$ \\
PLT $\left(10^{3} \mathrm{~mm}^{-3}\right)$ & $58.8 \pm 10.96$ & $134 \pm 17.32$ & $371.8 \pm 61.88^{* * *}$ & $126.8 \pm 13.68^{+++}$ & $291 \pm 77.81^{* * *}$ \\
WBC $\left(10^{3} \mathrm{~mm}^{-3}\right)$ & $2.47 \pm 0.35$ & $3.9 \pm 0.86$ & $5.88 \pm 0.82^{* * *}$ & $5.3 \pm 0.63^{* *}$ & $7.22 \pm 0.98^{* * *}$ \\
\hline
\end{tabular}

Values are means \pm SE for five rats in each group.

$\mathrm{DMH}, \mathrm{TQ}$, and different $(\mathrm{TQ}+\mathrm{DMH})$ groups versus control group: ${ }^{*} P<0.05,{ }^{* *} P<0.01$, and ${ }^{* * *} P<0.001$, TQ $+\mathrm{DMH}$ groups versus $\mathrm{DMH}$ : ${ }^{+} P<$ $0.05,{ }^{++} P<0.01$, and ${ }^{+++} P<0.001$.

TABLE 2: Malondialdehyde (MDA) and conjugated dienes (CD) levels in erythrocytes of adult rat controls or treated with DMH, TQ, and different $(\mathrm{TQ}+\mathrm{DMH})$ treatments.

\begin{tabular}{lccccc}
\hline & Control & TQ & DMH & Pretreatment & Posttreatment \\
\hline CD $^{\mathrm{a}}$ & $1.27 \pm 0.09$ & $1.4 \pm 0.25$ & $1.29 \pm 0.13$ & $1.24 \pm 0.04$ & $1.78 \pm 0.194^{* * *+++}$ \\
MDA $^{\mathrm{b}}$ & $13.11 \pm 0.75$ & $14.74 \pm 1.81$ & $20.59 \pm 0.54^{* * *}$ & $17.39 \pm 1.025^{* * *++}$ & $20.11 \pm 1.225^{* * *}$ \\
\hline
\end{tabular}

Values are means \pm SE for five rats in each group.

$\mathrm{DMH}, \mathrm{TQ}$, and different $(\mathrm{TQ}+\mathrm{DMH})$ groups versus control group: ${ }^{*} P<0.05 ;{ }^{* *} P<0.01 ;{ }^{* * *} P<0.001$, TQ + DMH groups versus DMH:

${ }^{+} P<0.05,{ }^{++} P<0.01,{ }^{++} P<0.001$.

${ }^{\mathrm{a}} \mu \mathrm{mol} / \mathrm{mg}$ of protein.

${ }^{\mathrm{b}} \mu \mathrm{mol}$ hydroperoxides/mg of protein.

treated group. The rats' exposure to DMH resulted in erythrocyte extensive oxidative damage as manifested by the significant increase $(P<0.05)$ in CAT, SOD, and GPx enzymes levels by $50.23 \%, 12.55 \%$, and $352.9 \%$, respectively, compared to control group. In contrast, the pretreatment decreases CAT, SOD, and GPx activities without reaching normal values. The posttreatment shows a similar activity to the DMH group in the different enzymes.

\section{Discussion}

In this study, the inhibitory effects of TQ on the hematological parameters changes and oxidative stress enzymes were observed in an experimental model of DMH-induced colon carcinogenesis. It was clearly indicated that the pretreatment with TQ in the presence of the procarcinogen DMH appreciably attenuates the alterations in the erythrocytes levels of lipid peroxidation and the overall antioxidant enzymatic status.

The DMH was usually used for the induction of colorectal carcinogenesis in rodents. It was metabolically activated in the liver by a series of reactions $[5,23]$. Blocking agents are chemopreventive agents that prevent tumorigenesis by blocking the carcinogen-DNA adduct formation [4]. Our study showed that $\mathrm{DMH}$ induced oxidative damages in erythrocytes, leading to hematotoxicity objectified by the reduction of $\mathrm{RBC}$ counts and $\mathrm{Hb}$ concentration. This could be the result of hematogenesis impairments by the inhibition of RBC production from proerythroblast and by erythrocyte destruction in hemopoietic organs. Several current medical drugs are extracted from herbs, and about one-quarter of prescription drugs contain at least one active compound derived from plant material. Herbal therapies, including the black seed (Nigella sativa) from which TQ is derived, have shown antitumor promotion activities in rats or mice treated with chemical carcinogens [3]. It suppresses benzo(a)pyrene(BP-) induced forestomach tumor formation [10], potentiates the antitumor activity of cisplatin, and improves its therapeutic index [24]. In this study we have observed that TQ pretreatment leads to an increase of RBC counts and $\mathrm{Hb}$ concentration to reach normal values.

The study conducted by Al-Amri and Bamosa had reported no significant systemic toxicities in adult patients with solid tumors or hematological malignancies who were treated with thymoquinone. Our results showed an increase of MDA and CD level and an overexpression of antioxidant enzyme activities. It clearly indicated that DMH had the potency to cause oxidative damage in erythrocytes. Antioxidant enzymes are considered to be the first line of cellular defense against oxidative damage. Among them, superoxide dismutase (SOD), catalase (CAT), and glutathione peroxidase $(\mathrm{GPx})$ mutually function in the effects of oxidant molecules limitation on tissues and are active in the defense against oxidative cell injury thanks to the fact that they are free radical scavengers [14]. Consequently, in the current study, it was suggested that the significant increase of the MDA and CD contents in the erythrocyte proved the overexpression of antioxidant defense system 
to limit the influx of ROS generated by DMH exposure. Enhanced MDA and CD associated with augmentation in detoxifying (GPx) and antioxidant (CAT, SOD) enzymes in the RBCs were observed in our study. These are the characteristic findings in malignant transformation $[25,26]$. It is evident from these results that, in DMH-treated rats, the oxidant-antioxidant homeostasis was disturbed. Woo et al. [27] have noted that thymoquinone could act as a free radical and superoxide radical scavenger, as well as preserving the activity of various antioxidant enzymes such as catalase, glutathione peroxidase, and glutathione-S-transferase. Our study shows that the pretreatment with TQ causes the depletion of antioxidant enzymes in RBCs to reach similar value to the control group especially in CAT and GPx. However, the posttreatment demonstrates a similar value to the DMH group especially in SOD and GPx. These enzymes work together to eliminate ROS where small deviations in physiological concentrations may have a dramatic effect on the resistance of cellular lipids, proteins, and DNA to oxidative damage. The antioxidant capability of thymoquinone has been implicated in the prevention of chemical-induced carcinogenesis. Numerous in vitro and in vivo studies have provided ample evidence that thymoquinone could prevent carcinogenesis and inhibit tumorigenesis through different molecular mechanisms [27]. The study of Ghali-Muhtasib et al. [3] indicates that TQ inhibits tumor-cell invasion in vitro with $\mathrm{IC}_{50}$ of $40 \mu \mathrm{M}$ as well as ACF formation and tumor development in DMH-induced mouse colon carcinogenesis and in a xenograft model of human HCT-116 colon cancer cells. Tumor growth inhibition by TQ in the DMH and xenograft mouse models may be attributed to its potent antiinflammatory and antioxidant effects.

\section{Conclusion}

The results from the present study show the beneficial role of the pretreatment with TQ in reducing some of the altered biochemical variables suggestive of oxidative stress in RBCs in $\mathrm{DMH}$ colon cancer. More studies have to be performed before thymoquinone can be developed into a drug for the potential treatment of various carcinomas and inflammatory disorders. Thus, clinical trials could be made with this agent with patients to enrich thymoquinone effects data in humans and to enhance its beneficial effect.

\section{Conflict of Interests}

The authors hereby declare that this paper has not been submitted elsewhere for publication, and that this study was performed according to the international rules considering animal experiments. The authors listed have read and approved this paper.

\section{Acknowledgments}

This paper was funded by the Tunisian Ministry of Scientific Research and Technology through the Research Unit of Human Nutrition \& Metabolic Disorders, USCR Mass
Spectrometry, Faculty of Medicine of Monastir, and the Research Unit of Cancer Biology and Genetics, Hematologic, and Autoimmune Diseases, Faculty of Pharmacy, Monastir, Tunisia.

\section{References}

[1] H. J. Harzallah, A. Neffati, I. Skandrani, E. Maaloul, L. ChekirGhedira, and T. Mahjoub, "Antioxidant and antigenotoxic activities of Globularia alypum leaves extracts," Journal of Medicinal Plant Research, vol. 4, no. 19, pp. 2048-2053, 2010.

[2] S. Marubayashi, K. Dohi, and T. Kawasaki, "Role of free radicals in ischemic rat liver cell injury: prevention of damages by vitamin E, coenzyme Q10, or reduced glutathione administration," Surgical, vol. 99, no. 2, pp. 184-192, 1985.

[3] H. Gali-Muhtasib, M. Ocker, D. Kuester et al., "Thymoquinone reduces mouse colon tumor cell invasion and inhibits tumor growth in murine colon cancer models," Journal of Cellular and Molecular Medicine, vol. 12, no. 1, pp. 330-342, 2008.

[4] T. Devasena, V. P. Menon, and K. N. Rajasekharan, "Prevention of 1,2-dimethylhydrazine-induced circulatory oxidative stress by bis-1,7-(2-hydroxyphenyl)-hepta-1,6-diene-3,5dione during colon carcinogenesis," Pharmacological Reports, vol. 58, no. 2, pp. 229-235, 2006.

[5] M. Perše and A. Cerar, "Morphological and molecular alterations in 1,2 dimethylhydrazine and azoxymethane induced colon carcinogenesis in rats," Journal of Biomedicine and Biotechnology, vol. 2011, Article ID 473964, 14 pages, 2011.

[6] M. Lipkin, B. Reddy, H. Newmark, and S. A. Lamprecht, "Dietary factors in human colorectal cancer," Annual Review of Nutrition, vol. 19, pp. 545-586, 1999.

[7] Y. J. Surh, "Cancer chemoprevention with dietary phytochemicals," Nature Reviews Cancer, vol. 3, no. 10, pp. 768-780, 2003.

[8] H. Jrah Harzallah, B. Kouidhi, G. Flamini, A. Bakhrouf, and T. Mahjoub, "Chemical composition, antimicrobial potential against cariogenic bacteria and cytotoxic activity of Tunisian Nigella sativa essential oil and thymoquinone," Food Chemistry, vol. 129, no. 4, pp. 1469-1474, 2011.

[9] O. A. Badary and A. M. Gamal El-Din, "Inhibitory effects of thymoquinone against 20-methylcholanthrene-induced fibrosarcoma tumorigenesis," Cancer Detection and Prevention, vol. 25, no. 4, pp. 362-368, 2001.

[10] O. A. Badary, O. A. Al-Shabanah, M. N. Nagi, A. C. Al-Rikabi, and M. M. A. Elmazar, "Inhibition of benzo(a)pyrene-induced forestomach carcinogenesis in mice by thymoquinone," European Journal of Cancer Prevention, vol. 8, no. 5, pp. 435-440, 1999.

[11] O. A. Badary, "Thymoquinone attenuates ifosfamide-induced Fanconi syndrome in rats and enhances its antitumor activity in mice," Journal of Ethnopharmacology, vol. 67, no. 2, pp. 135$142,1999$.

[12] O. A. Badary, M. N. Nagi, O. A. Al-Shabanah, H. A. Al-Sawaf, M. O. Al-Sohaibani, and A. M. Al-Bekairi, "Thymoquinone ameliorates the nephrotoxicity induced by cisplatin in rodents and potentiates its antitumor activity," Canadian Journal of Physiology and Pharmacology, vol. 75, no. 12, pp. 1356-1361, 1997.

[13] M. Kurata, M. Suzuki, and N. S. Agar, "Antioxidant systems and erythrocyte life-span in mammals," Comparative Biochemistry and Physiology B, vol. 106, no. 3, pp. 477-487, 1993.

[14] A. Nakbi, W. Tayeb, S. Dabbou et al., "Dietary olive oil effect on antioxidant status and fatty acid profile in the erythrocyte 
of 2,4-D-exposed rats," Lipids in Health and Disease, vol. 9, article no. 89, 2010.

[15] J. Harvey, The Erythrocyte: Physiology, Metabolism and Biochemical Disorders, Academic Press, London, UK, 1997.

[16] M. Sinha, P. Manna, and P. C. Sil, "A $43 \mathrm{kD}$ protein from the herb, Cajanus indicus L., protects against fluoride induced oxidative stress in mice erythrocytes," Pathophysiology, vol. 14, no. 1, pp. 47-54, 2007.

[17] M. M. Bradford, "A rapid and sensitive method for the quantitation of microgram quantities of protein utilizing the principle of protein dye binding," Analytical Biochemistry, vol. 72, no. 1-2, pp. 248-254, 1976.

[18] K. Yagi, "A simple fluorometric assay for lipoperoxide in blood plasma," Biochemical Medicine, vol. 15, no. 2, pp. 212-216, 1976.

[19] H. Esterbauer, G. Striegl, H. Phul, and M. Rotheneder, "Continuous monitoring of in vitro oxidation of human low density lipoprotein," Free Radical Research Communications, vol. 6, no. 1, pp. 67-75, 1989.

[20] A. Clairbone, "Catalase activity," in Handbook of Methods for Oxygen Radical Research, pp. 283-284, CRC Press, Boca Raton, Fla, USA, 1985.

[21] C. Beauchamp and I. Fridovich, "Superoxide dismutase: improved assays and an assay applicable to acrylamide gels," Analytical Biochemistry, vol. 44, no. 1, pp. 276-287, 1971.

[22] L. Flohe and W. A. Gunzler, "Assays of glutathione peroxidase," Methods in Enzymology, vol. 105, pp. 114-121, 1984.

[23] W. W. L. Chang, "Histogenesis of colon cancer in experimental animals," Scandinavian Journal of Gastroenterology, Supplement, vol. 19, no. 104, pp. 27-43, 1984.

[24] S. C. Nair, M. J. Salomi, B. Panikkar, and K. R. Panikkar, "Modulatory effects of Crocus sativus and Nigella sativa extracts on cisplatin-induced toxicity in mice," Journal of Ethnopharmacology, vol. 31, no. 1, pp. 75-83, 1991.

[25] F. Della Rovere, A. Granata, A. Saija et al., "-SH groups and glutathione in cancer patient's blood," Anticancer Research, vol. 20, no. 3 A, pp. 1595-1598, 2000.

[26] G. Ray, S. Batra, N. K. Shukla et al., "Lipid peroxidation, free radical production and antioxidant status in breast cancer," Breast Cancer Research and Treatment, vol. 59, no. 2, pp. 163 $170,2000$.

[27] C. C. Woo, A. P. Kumar, G. Sethi, and K. H. B. Tan, "Thymoquinone: potential cure for inflammatory disorders and cancer," Biochemical Pharmacology, vol. 83, no. 4, pp. 443-451, 2012. 


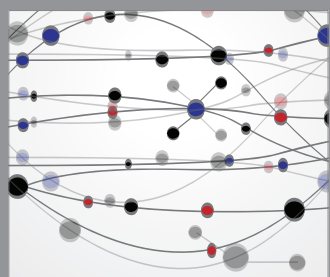

The Scientific World Journal
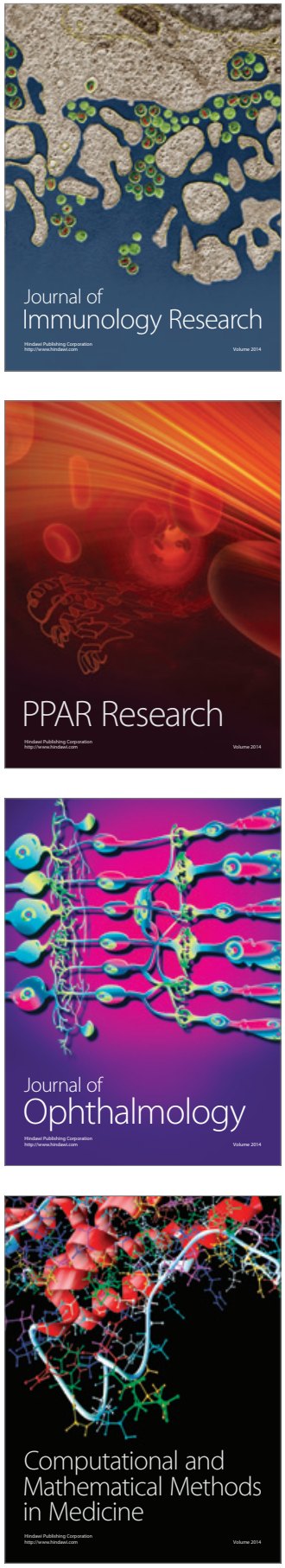

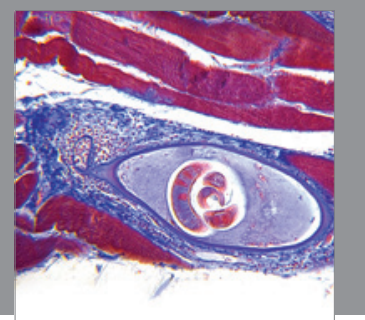

Gastroenterology

Research and Practice
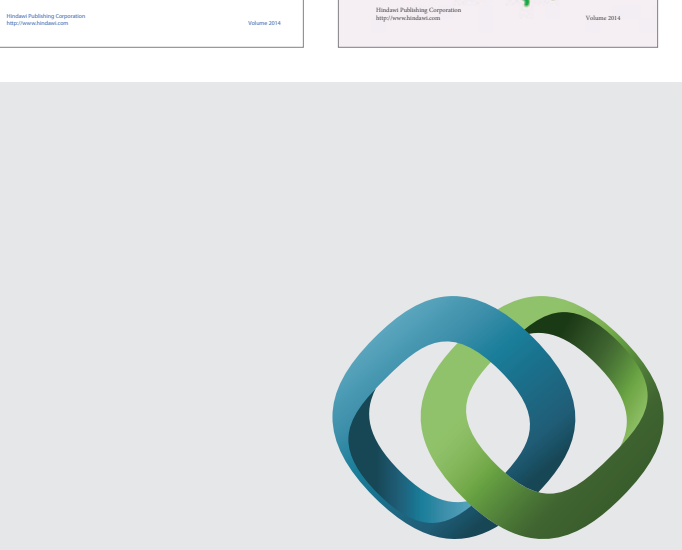

\section{Hindawi}

Submit your manuscripts at

http://www.hindawi.com
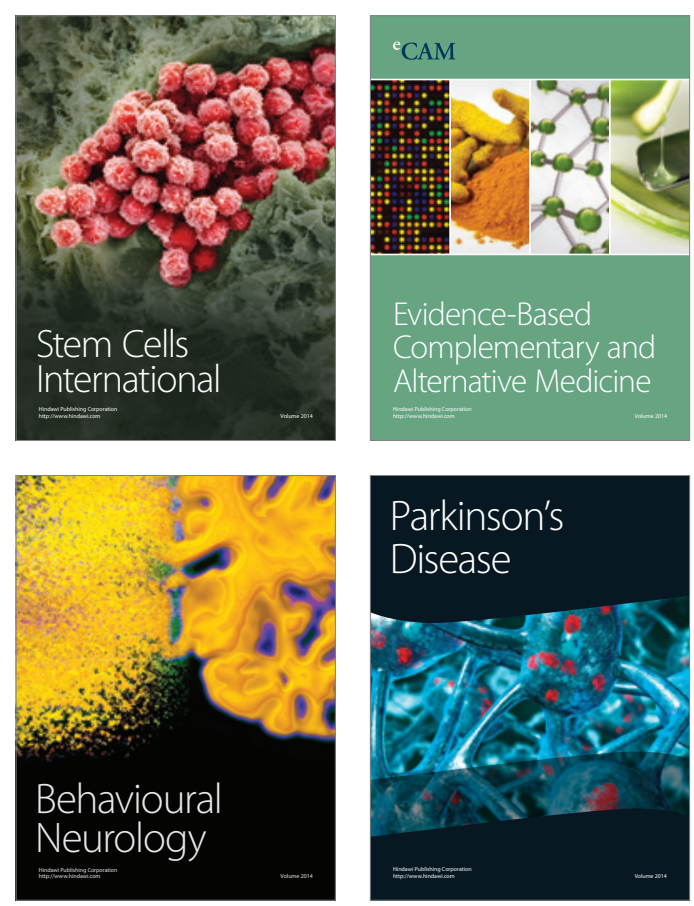

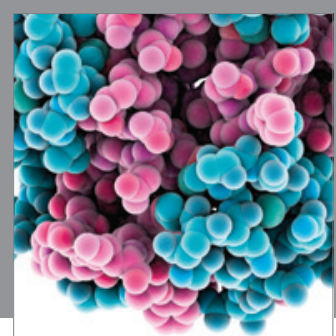

Journal of
Diabetes Research

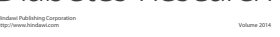

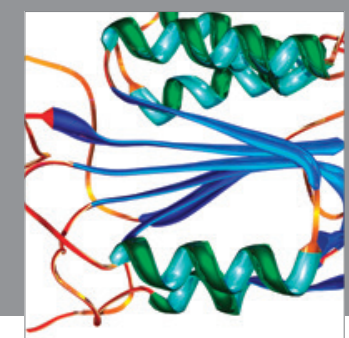

Disease Markers
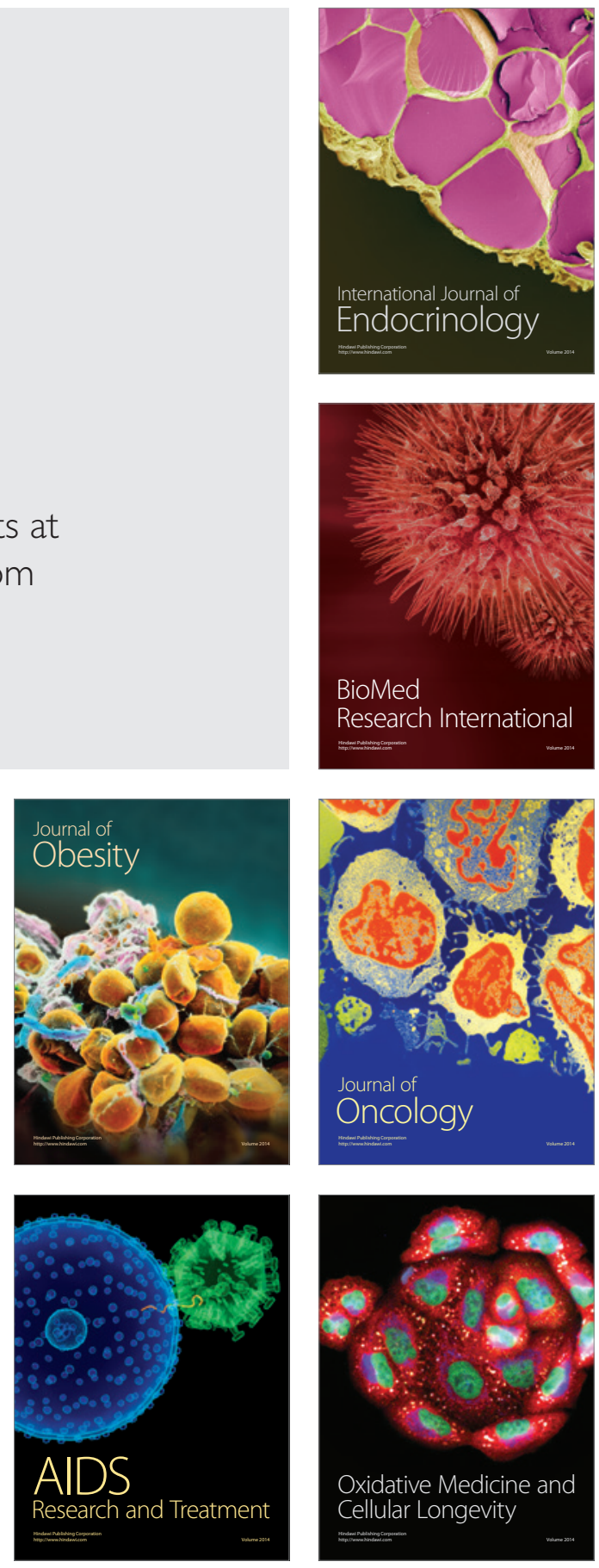